\title{
INVESTIGAÇÃO ACERCA DO CONCEITO DE SIMBOLISMO NO INTERIOR DA PSICANÁLISE*
}

Francisco Verardi Bocca**

\section{RESUMO}

Este artigo apresenta uma investigação sobre o conceito de simbolismo como concebido por Freud, além de seu colaborador Ernest Jones. O resgate acerca do conceito de simbolismo, que envolve averiguar seu estatuto, constituição, mecanismo de funcionamento, articulações, origens, influências, deve permitir o reconhecimento de seu papel no interior da própria elaboração freudiana.

Palavras-chave: psicanálise; linguagem; simbolismo; sonho; sintoma.

\section{INTRODUÇÃO}

Conceito bastante controverso na obra de Freud, o simbolismo, a despeito de sua validade questionada por muitos de seus leitores, lembremos, nunca foi por ele abandonado, inclusive persistindo ao longo dos desdobramentos de sua obra, como demonstraremos ao longo da exposição.

Diante de tal circunstância, julgamos oportuno empreender uma pesquisa que aponte sua história, bem como sua articulação com as teses que lhe deram sustentação. Procuraremos apontar os temas que estão a ele relacionados, como sua concepção como operador das linguagens do sonho, do sintoma e, por extensão, da cultura. Ainda, a sexualidade infantil, as noções de hereditariedade e, inclusive, o papel que Freud e Jones lhe atribuiram relativamente à técnica de interpretação. Apontar, por fim, as motivações e os interesses de Freud em sustentá-lo, bem como a contri-

\footnotetext{
* Artigo recebido em 12/5/2005 e aprovado em 11/8/2005.

** Professor de Ética do Programa de Mestrado em Filosofia da PUC-PR. E-mail: francisco.bocca@pucpr.br
} 
buição de seu colaborador Ernest Jones, evidentemente excetuando outros como Stekel e Jung, dada a brevidade e concisão que o espaço de um artigo demanda.

Certos de seu caráter introdutório, passemos a ela.

\section{O SONHO DE FREUD}

Comecemos nossa investigação pela obra Interpretação dos sonhos. É preciso assinalar antes de tudo que Freud concebeu o sonho como um ato mental constituído por uma seqüência de eventos que se articulam segundo uma ordem própria, o que lhe confere sentido. Assim, fica desde já registrada a recusa do sonho, diz ele, "como um processo somático que assinala sua ocorrência por indicações registradas no aparelho mental" (1969c, p. 131). Por conta disso, o sentido do sonho não pode ser buscado em um referente somático, mas no interior da própria cadeia psíquica. Isso de fato instaura um dos pontos de vista originais de Freud sobre os sonhos. Contudo, não se pode deixar de esclarecer que o propósito de uma interpretação expressa sim a idéia de que cada sonho é dotado de sentido, sendo que ele não se dá senão segundo cada sonhador, ficando o caso do simbolismo à parte, como veremos adiante.

Nesses termos, a aparente falta de sentido do sonho só foi anteriormente passível de sustentação na medida em que não se havia considerado até então o comando da consciência moral que conduz o sujeito à adoção de um disfarce em relação a seus próprios desejos. Assim, uma nova articulação se apresenta; desejo e disfarce deste. Mas pode-se ainda perguntar como e porquê da forma ou apresentação enigmática que um sonho se vale para a realização de um desejo. Essa perspectiva é que abre a investigação relativa às alterações pelas quais passam os pensamentos oníricos para atingirem a tal forma enigmática do sonho manifesto, inclusive o simbolismo, que nada apresenta de imediatamente explícito e compreensível para a consciência desperta.

Abriu-se aqui uma frente de argumentação para identificar a presença de uma censura e de uma resistência que a acompanha, sendo a distorção onírica uma conseqüência delas, bem como pavimentou-se o terreno para anunciar a presença e a disposição de uma das alternativas do disfarce onírico, o recurso ao símbolo. No entanto, muito ainda há que 
ser dito antes de nele nos determos. Na tentativa de avançar na argumentação, digamos, citando Freud, que

os sonhos recebem sua forma em cada ser humano mediante a ação de duas forças psíquicas e que uma delas constrói o desejo que é expresso pelo sonho, enquanto a outra exerce uma censura sobre este desejo onírico e, pelo emprego dessa censura, acarreta forçosamente uma distorção na expressão do desejo. (1969c, p. 178)

Agora, para o propósito de reconhecer o estatuto da linguagem do sonho, esclareçamos que seu modo de representação de fato nunca é realizado de forma aleatória, justamente o que inviabilizaria sua definição como linguagem, isto é, como algo que porte uma mensagem ainda que distorcida de uma instância à outra. Sendo assim, devemos conceber com Freud que a forma manifesta do sonho, a despeito de sua aparência quase sempre desconcertante, "deve possuir algum atributo que a torne especialmente adequada para esse fim" (1969c, p. 209), isto é, deve apresentar algum ponto de contato entre as partes envolvidas, alguma identidade que a análise deve revelar.

$\mathrm{O}$ atributo que torna adequado ou viabiliza o acesso do material latente à consciência ocorre, nessa perspectiva, sempre mediante elos facilitadores, já que o conteúdo manifesto pode, de alguma forma, pertencer "ao círculo de representações que cercam o verdadeiro instigador do sonho" (1969c, p. 210), por exemplo, um preservativo ser representado por um sobretudo, como diz Freud, "visto que nos enfiamos em ambos" (1969c, p. 216). Com esse exemplo fica antecipada a referência às formas de reenvio presentes nos sonhos.

Nesse sentido, o sonho é aqui entendido como derivado de um pensamento reprimido, embora, a princípio, Freud não tivesse clareza sobre as causas de tal repressão, que, ao ser realizado sem disfarces, promoveria por sua imoralidade o despertar do sono. Lembre-se que esta só foi esclarecida suficientemente após identificar a sexualidade infantil descrita em Três ensaios sobre a teoria da sexualidade, de 1905, como fonte de fenômenos psíquicos. Relembre-se que, a princípio, na primeira edição da Interpretação dos sonhos, o pensamento reprimido ainda parecia estar identificado como sendo o diurno no tempo de vigília. Somente nas reedições, Freud atribuiu com mais clareza a etiologia do pensamento reprimido, ou dos desejos mantidos sob recalque, desvendando o mecanismo e a etiologia da repressão. 
Na construção dessa perspectiva, até onde Freud sustentou uma concepção dualista das pulsões, que seriam a sexual e a do ego, o sonho realiza, primordialmente, o desejo de continuar dormindo, que é próprio da pulsão do ego, uma das forças psíquicas em jogo ao lado da pulsão sexual. No interior dessa concepção, uma vez prevalecendo a pulsão do ego, na medida em que o sujeito não acorda sob a proteção do sonho, para que a pulsão sexual se manifeste, ela se submete a uma deformação (conciliação) do material tomado à experiência atual, transformação esta que vai definir um produto novo, isto é, sua forma como conteúdo manifesto, estabelecendo assim suas condições de aparição no sonho, ou, ainda, de se dar à consciência como linguagem sempre fragmentária e enigmática.

Essa perspectiva cria condições para a identificação do sonho com o sintoma, o que é realizado na Interpretação dos sonhos, quando elucida a formação de ambos como ligados à sexualidade infantil, sobre a qual incide a repressão. Nesse sentido, o sonho como o sintoma são ambos concebidos como realização de desejo, já que são assim entendidos como uma repetição das experiências pré-históricas (pré-genitais) revividas (revitalizadas) por intermédio da conexão com experiências recentes que funcionam como provedoras de material figurativo. Destinam-se, como na própria definição de fantasia dada por Freud em sua obra História do movimento psicanalítico, "a encobrir a atividade auto-erótica dos primeiros anos de infância” (p. 28), por trás da qual emerge a vida sexual da criança. Entende-se agora por quais motivos o sonho é reprimido: ele é entendido como uma memória erótica, já que se sonha com o próprio corpo em uma fase já concebida como sexualizada. Nesse ponto, devemos reconhecer a existência e o amadurecimento de pelo menos duas teses adicionais, a saber, a atribuição de um desejo infantil realizado a cada sonho e a afirmação de disfarce conseqüente desse mesmo desejo. A esta altura, pressupomos a necessidade de esclarecimentos a respeito da articulação que promove o disfarce, a saber, o trabalho do sonho, como Freud chamou.

No capítulo da Interpretação dos sonhos que Freud dedicou a descrevê-la, a primeira coisa que fez notar em auxílio à sua argumentação foi o reconhecimento de uma desproporção entre a riqueza do pensamento onírico e a brevidade do conteúdo do sonho. Tal desproporção pode ser reconhecida quando se observa, durante a análise do relato do sonho, o quanto as associações produzidas a partir deste são numericamente 
maiores em relação aos elementos sonhados. Deve-se, em função disso, reconhecer a presença de um operador que promoveu uma condensação desse material todo, a título de apresentá-lo sinteticamente. Nessa ótica, esse mecanismo condensador pode ser entendido como um procedimento cuja finalidade é a de evitar que, como ele mesmo diz, "o sonho não seja uma tradução fiel ou uma projeção ponto-por-ponto dos pensamentos do sonho, mas uma versão altamente incompleta e fragmentária deles" (1969, p. 307). Sobre tal operação, que veio a ser chamada condensação, Wollheim observou que ela impede a correspondência nítida, de um a um, entre os conteúdos manifesto e latente do sonho. Em função disso, ela provoca o que chamou, valendo-se da terminologia freudiana, de sobredeterminação, de forma que para qualquer conteúdo manifesto dado, pode ou deve haver mais de um latente, isto é, qualquer sonho pode expressar muitos desejos distintos. Nesse sentido é que se pode dizer que a condensação complica a "gramática" do sonho, multiplicando-a, desdobrando-a.

A noção de trabalho do sonho deve agora receber o acréscimo da descrição de seu segundo modus operandi, a saber, o mecanismo do deslocamento. Esse, como concebido por Freud, aponta para um segundo tipo de relação entre os conteúdos latente e manifesto, por ocasião da qual "os elementos que se destacam como os principais componentes do conteúdo manifesto do sonho estão longe de desempenhar o mesmo papel nos pensamentos do sonho" (1969c, p. 331). O mecanismo do deslocamento levado a efeito pelo trabalho do sonho consiste assim no artifício de despojar de intensidade elementos que receberam grande valor psíquico, colocando em seu lugar outros elementos de valor muitas vezes desprezível, cuja presença se faça, e isto é o esperado, indiferente à censura.

Pode-se agora, reunindo as informações até aqui apresentadas, afirmar que o mecanismo de deslocamento, bem como o de condensação podem ser considerados como sendo os dois fatores dominantes, como diz Freud, "a cuja atividade podemos, em essência, atribuir a forma assumida pelos sonhos" (1969c, p. 333). Além desses, acrescentemos, há um terceiro fator de representabilidade do qual se vale o trabalho do sonho. Trata-se do mecanismo que opera a transformação de pensamentos oníricos em imagens visuais, figurando-as. Essa transposição, em apoio ou aliança com os interesses dos dois outros mecanismos apresentados 
acima, pode ser vista como de grande valia para os propósitos do sonho, já que torna indiscutivelmente mais ricas as associações representadas.

Para concluir sobre os diferentes modos de operação do trabalho do sonho, acrescente-se agora a menção que Freud faz à forma de representação simbólica. Contudo, pela importância que lhe foi conferida, receberá no próximo tópico explicitação.

\section{PRESENÇA do SÍMBolo}

A consideração da presença de um simbolismo também chamado por Freud de típico nos sonhos suscita a seguinte indagação, que merece atenção: ocorreriam nos sonhos símbolos com significado fixo? Uma vez respondida afirmativamente, decorreria, que a compreensão de tais símbolos comportaria uma decifração e não uma interpretação, procedimentos que o próprio Freud, no segundo capítulo de seu livro sobre os sonhos, distinguiu como dois métodos possíveis, mas divergentes, de abordagens dos símbolos.

Para superação desse impasse, podemos nos valer preliminarmente de uma discussão cuja finalidade é a de auxiliar sua compreensão. Tratase de investigar a história (ou a pré-história) do interesse de Freud pelo simbolismo, mesmo porque, segundo Wollheim, esse tema já estava mencionado no texto original da Interpretação dos sonhos, recebendo posteriormente maior atenção e conseqüente reelaboração. Enfoquemos a importância dada ao simbolismo por Freud a partir da oposição apresentada por ele no segundo capítulo da Interpretação dos sonhos, entre a interpretação simbólica e o método de decifração. Por conta disso, devemos dizer antecipadamente que sua elaboração de uma técnica psicanalítica deu-se em meio à consideração desses dois métodos tradicionais. Antecipemos que, como sugere Garcia-Roza, o método decifrativo seria o mais próximo do método psicanalítico.

Acompanhando atentamente o segundo capítulo da Interpretação dos sonhos, observa-se que, na análise e no comentário sobre outras teorias e métodos de interpretação de sonhos, Freud reconhece que o mundo leigo tem-se servido de dois métodos essencialmente diferentes. O primeiro, já mencionado, é o da interpretação simbólica dos sonhos, que consiste em tomar o conteúdo do sonho como um todo e substituí-lo por outro que seja compreensível. É o caso, por exemplo, da interpretação 
do sonho do faraó proposta por José na Bíblia. Sobre essa concepção, Freud reconhece uma impossibilidade de, como ele diz, "se dar instruções sobre o método de se chegar a uma interpretação simbólica" (1969c, p. 132), já que seria uma atividade mais artística do que científica, pois dependeria da posse de dons particulares, como intuições do intérprete, não carecendo do recurso ao sonhador. Essa operação estaria em desacordo com a técnica que Freud, já àquela época, desenvolvia.

Quanto ao segundo método, o da decifração, este trataria os sonhos "como uma espécie de criptografia, em que cada signo pode ser traduzido por outro de significado conhecido, de acordo com um código fixo" (FrEUD, 1969 c, p. 132). Nesse caso, a decifração proposta seria elaborada em parcelas isoladas ou destacadas dos conteúdos do sonho e não como um todo. Como ele mesmo diz, "como se o sonho fosse um conglomerado geológico em que cada fragmento de rocha exigisse uma análise isolada" (FreUd, 1969c, p. 134).

Deve ficar claro que tais métodos populares de abordagem interpretativa dos sonhos não são compreendidos como procedimentos científicos, pois o primeiro, como o próprio Freud aponta, tem uma aplicação restrita, já que só se aplicaria aos sonhos de muita clareza e nitidez, além de ser impraticável uma tentativa de elaboração conceitual sobre ele. Quanto ao segundo, também dependeria da confiabilidade do código disponível, o que não parece nada seguro para um procedimento que se quer objetivo. Contudo, desses, em especial o segundo, o decifrativo, Freud identifica e destaca positivamente seu aspecto decomponível, isto é, a fragmentação em partes do conteúdo do sonho, o que sugere seu aproveitamento e sua contribuição para a elaboração de seu próprio método. Sobre esse aspecto, em suas conferências sobre sonhos, de 1915, ao analisar uma técnica de abordagem e interpretação de sonhos, Freud propõe que se considere a multiplicidade de elementos que comportam, o que demandaria uma divisão deles para que a pesquisa seja feita em cada elemento à parte e não em bloco ou no todo, o que evidencia mais uma vez uma identidade, ainda que cautelosa, em relação ao método decifrativo. Assim, a proximidade anteriormente referida por Garcia-Roza em relação ao segundo método, e a recusa do primeiro, se justifica, como dito, pelo fato de o método da decifração levar em conta o detalhe ou a parte - e não a massa ou o bloco.

Contudo, de fato, o método efetivamente proposto por Freud não é, como ele mesmo diz, "tão cômodo quanto o método popular de 
decifração, que traduz qualquer parte isolada do conteúdo do sonho por meio de um código fixo" (1969c, p. 139). Igualmente longe de recusar o simbolismo nos sonhos, o que de fato Freud recusa no método leigo da interpretação simbólica dos sonhos é justamente a utilização de uma chave de leitura. Ele a reconhece e denuncia como aleatoriamente escolhida pelo intérprete, enquanto ele próprio, segundo uma perspectiva científica, busca resgatar e identificar tais chaves, por exemplo, como algo "conhecido e estabelecido pelo uso lingüístico consagrado" (1969c, p. 351).

Ora, Freud acabou mais tarde reconhecendo que o trabalho do sonho vale-se também de um certo simbolismo na operação do pensamento latente em manifesto, "o que torna possível solucionar no todo ou em parte esse tipo de sonho, até mesmo independentemente das informações do sonhador" (1969c, p. 352). A partir daqui é que a escalada começa a ficar íngreme, pois há um resgate, ainda que parcial, de ambos os métodos. Dessa forma, o tema do simbolismo surge ainda com mais força na medida em que o processo que promove a deformação nos sonhos é enfocado. A esse respeito, logo no início da Conferência $X$, Freud reconhece que a censura não seria o único fator responsável pela deformação onírica. Assim, retirando-lhe a exclusividade, aponta para um outro fator que possa produzir o mesmo resultado; ao final dessa mesma conferência, declara que "o simbolismo é um segundo e independente fator de deformação de sonhos, ao lado da censura de sonhos" (p. 170).

É curioso notar e imperioso declarar que tal fator foi apontado, descoberto ou evidenciado na medida em que Freud reconheceu a presença de uma lacuna em sua técnica de interpretação. Diz ele, na mesma conferência, que algumas vezes "acontece não ocorrer à pessoa em análise nenhuma idéia em resposta a determinados elementos de seus sonhos" (p. 151). Essa situação analítica, em que o sonhador pode responder, por exemplo, que nada lhe ocorre, é justamente a que abrirá o campo para o reconhecimento da presença de símbolos. Contudo, a justificativa vem a seguir, pois longe de ser nesses casos uma falha da técnica, está-se sim, reconhece Freud, diante de "um novo princípio geral" (p. 152). Essa seria uma situação em que nos orientaríamos para o reconhecimento da presença de algo como um símbolo típico. Em um parágrafo acrescentado em 1914 à sua Interpretação dos sonhos, diz que esse fato ocorre na medida em que 
ao tentarmos interpretar um sonho típico, o sonhador, em geral, deixa de produzir as associações que em outros casos nos levariam a compreendê-lo, ou então suas associações tornam-se obscuras e insuficientes. (p. 269)

A compreensão do argumento teórico que justifica essa postura metodológica de Freud pode ser encontrada no sétimo capítulo da Interpretação dos sonhos, quando trata do tópico do esquecimento dos sonhos. Freud nele argumenta que a dúvida, a desconfiança, a incerteza e a própria interrupção do relato associativo apontam para a presença de um instrumento da resistência psíquica. Nesse aspecto, há algo verdadeiramente novo na medida em que denuncia a impropriedade do material que foi admitido na consciência, impropriedade esta que só pode ser compreendida quando se relaciona tal material com sua natureza sexual, e por isso reprimida, o que só evidencia o poder e a necessidade da censura psíquica, já que o esquecimento ou a interrupção serve ao propósito combinado da censura e da resistência. Contando com o alcance que essa concepção oferece para compreender a interrupção do relato do sonho, abre-se espaço para detectar a presença de um símbolo, já que este mais do que, ou tanto quanto qualquer outra representação, deve satisfazer ao propósito da censura e da resistência.

Segundo e seguindo esse princípio, nos casos em que um símbolo aparece, admite Freud, uma vez identificado, "conseguimos traduções uniformes para numerosos elementos oníricos" (p. 152), isto é, substituições constantes e regulares. Essa expectativa recebe justificativa justamente na afirmação de Freud de que em todos nós "há um certo número de sonhos que quase todo mundo tem da mesma forma e que estamos acostumados a presumir que tenham o mesmo sentido para todos" (1969c, p. 269). Essa afirmação leva à crença de uma natureza comum para todo esse elenco de sonhos. A realidade admitida por Freud, acerca da presença do símbolo típico, estabelece um método de interpretação diferente do baseado na livre associação e que pode ocorrer nesse caso, segundo admite, sem as associações fornecidas pelo sonhador, isto é, para ele "é possível solucionar no todo ou em parte esse tipo de sonhos, até mesmo independentemente das informações do sonhador" (1969c, p. 373). Desse modo, observa-se que Freud trata de propor uma técnica combinada que deve suplementar a da livre associação, isto é, a interpretação ganha amplitude na medida em que concilia 
o método associativo com a decifração simbólica, esta última segundo as ressalvas já apresentadas.

Nesses termos é que compreendemos a definição relativa à relação entre o conteúdo onírico e sua versão simbólica, isto é, do símbolo como elemento representante do pensamento onírico latente e inconsciente. A presente relação simbólica seria nesse caso, como já apontado anteriormente, a quarta possibilidade de relação entre os elementos do sonho, além da condensação, do deslocamento e da representação plástica ou figurada.

Prematuramente, digamos, na tentativa de começar a estabelecer desde já um quadro distintivo em relação às outras formas de representação indireta presentes no sonho, que a representação simbólica assume um aspecto diferenciado, já que sua ligação com seu representado hoje observada já teria ocorrido, como diz Freud, "em épocas pré-históricas pela identidade conceitual e linguística" (1969c, p. 360), portanto somos tentados a concluir que não poderia ser fruto de uma ação individual ou exclusiva promovida por parte de quem sonha, o que merece reflexão. Posto isso, consideremos a natureza histórica da constituição de tal simbolismo, uma vez que, adicionalmente, enquanto alguns símbolos se apresentam, como sugerido por Freud, tão antigos quanto a própria linguagem natural, outros vão sendo cunhados e estabelecidos continuamente ao longo do tempo. Resta saber a natureza dessa cunhagem e desse estabelecimento.

Contudo, lembremos que tais símbolos que aqui foram apresentados em um sentido estável ou típico, o que lhes confere a princípio uma universalidade e uma impessoalidade, podem também seguir motivos individuais, isto é, serem tomados em um sentido próprio segundo lembranças particulares da vivência do sonhador, o que demandaria mais uma vez uma articulação sua com as associações fornecidas pelo sonhador. Em função disso, devemos considerar se tal reconhecimento impediria de levar adiante a pretensão de elaboração de uma gramática do sonho, inspirada, por exemplo, no método de decifração, segundo a pretensão freudiana acima manifestada.

Por conta disso, a consideração acerca da presença de símbolos no sonho exigiu de Freud uma distinção dos sonhos típicos em duas classes, "os que realmente têm sempre o mesmo sentido e os que, apesar de terem conteúdo idêntico ou semelhante, devem, não obstante, ser 
interpretados de maneira extremamente variada" (1969c, p. 418). Atentese para o fato de que a classe de símbolos que comportam significados permanentemente fixos permitiria a elaboração de um dicionário de sonhos, já que estes poderiam, nessa ótica, ser comparáveis, como sugeriu Freud, em um arroubo de otimismo, aos logogramas da taquigrafia. Podese assim concluir que tudo isso concorreria para restaurar ou recuperar, pelo menos em alguns de seus aspectos, o antigo método de decifração.

Para esclarecer essa questão, reconheçamos que a interpretação do sonho de outra pessoa depende do acesso ao material associativo que o sonhador fornece ao analista. Mas haveria casos apontados por Freud em que a interpretação independeria dessas informações, isto é, justamente "quando o sonhador emprega elementos simbólicos no conteúdo do sonho" (1969c, p. 256), diz ele. Esse ponto de vista admite que primeiro "cada pessoa tem liberdade de construir seu mundo onírico segundo suas peculiaridades individuais" (Freud, 1969c, p. 256) e em segundo lugar que "há um certo número de sonhos semelhantes produzidos por quase todo mundo" (Freud, 1969c, p. 256) que presumivelmente teriam o mesmo sentido para todos e que, inclusive, decorreriam das mesmas fontes em todos os casos. Nesse caso, as associações livres talvez fossem mesmo dispensáveis, já que o símbolo utilizado é concebido como preexistente. No entanto, mais uma vez, deve haver um motivo privado para a sua eleição e o seu uso, o que restabeleceria a importância das associações que denunciariam os motivos da escolha.

Todavia, trata-se, como é possível observar, da consideração de que existem certas invariantes ou mesmo cristalizações nas representações oníricas, de modo que certos pensamentos ou certas preocupações de natureza básica encontram uma forma regular de expressão, por exemplo, pais representados por reis e rainhas, pênis por guarda-chuvas, úteros por armários ou caixas etc. A esse respeito, Freud reconhece que a gama de coisas representáveis simbolicamente nos sonhos não é muito extensa, seriam o corpo humano como um todo, pais, filhos, irmãos e irmãs, nascimento, morte, nudez e algumas outras mais.

Reforcemos a idéia de que foi com base na consideração e no reconhecimento de sonhos típicos que Freud voltou sua atenção para o sentido particular do simbolismo. A partir deles, ele pôde reconhecer a ausência de uma produção simbólica no interior das funções próprias do mecanismo que chamou trabalho do sonho, no qual operam deslocamento, condensação e figuração. Queremos dizer que no caso específico de 
uma representação simbólica, no que diz respeito à atuação do trabalho do sonho, este, segundo Freud, "nada fez de original, ao efetuar essas substituições [...] ele simplesmente percorre as vias já estabelecidas no inconsciente..." (1969c, p. 377). É justamente nesse contexto que o simbolismo foi considerado por Freud como um quarto recurso utilizado, mas não produzido, já que ele recusa a possibilidade de atuação do trabalho do sonho como produtor de símbolos. Tal reconhecimento foi expresso por Freud da seguinte maneira:

Todos os exemplos de símbolos no sonho levaram-me à mesma conclusão: não é necessário postular a existência, no trabalho do sonho, de uma atividade simbolizadora peculiar da mente no trabalho do sonho, o sonho se serve de quaisquer simbolismos que já se encontram presentes no pensamento inconsciente. (1969c, p. 358)

Quer com isso dizer que o sonhador tem à sua disposição formas simbólicas de expressão e as utiliza para atingir seus objetivos, como o de conseguir substitutos ou representações levando em conta a censura. Nesse sentido, Freud concluiu que "o simbolismo é um segundo e independente fator de deformação dos sonhos, ao lado da censura dos sonhos" (1969i, p. 170), visto que este contribui para o caráter aparentemente estranho e incompreensível dos sonhos.

Por conta disso, pode-se dizer que os sonhos valem-se também desse simbolismo para a representação disfarçada de seus pensamentos latentes. Acrescente-se que um material inconsciente, pelo fato de ter sido reprimido ou recalcado, deseja tornar-se consciente, manifestandose além do caso particular dos sonhos, também nos chistes, nos sintomas neuróticos, nos atos falhos, nas artes em geral, na linguagem cotidiana, entre outros, razão pela qual pode-se conceber uma comunidade de símbolos reconhecíveis e identificáveis como igualmente presentes nesses diversos campos dos fatos humanos. As pesquisas de Freud apontaram para um simbolismo fixo que acabou, como dito, por não se mostrar peculiar e exclusivo dos sonhos, mas detectáveis em diferentes manifestações culturais.

Resta, contudo, a tarefa de esclarecer a partir de que processos são construídos os símbolos, além de como são incorporados pelo inconsciente que dispõe deles para elaboração do sonho, entre outras manifestações. Posto esse desafio, decorre que é a própria pré-história 
do sujeito, como da espécie, que exige uma atenção especial a fim de que seja distinguido o tipo de representação simbólica aqui enfocada de outras formas de representação indireta. Além disso, percebe-se também que a noção de pré-história, quer do sujeito, quer da espécie, esclarecese com a história da própria evolução da noção de símbolo, o que exige a consideração mais detida de alguns aspectos do pensamento de Ernest Jones. Com o propósito de esclarecer a questão, será dada a seguir uma atenção a seus argumentos. Adiantemos que, para tanto, será necessário em acréscimo o recurso à consideração da natureza das pulsões, bem como do que se pode chamar destinos das pulsões, particularmente no que diz respeito à sua relação com a produção do símbolo, o que será incluído de forma intercalada, sempre que necessário.

\section{PRODUÇÃo DO SÍMBOLO}

De início, enfocaremos um artigo de Jones com o título "La théorie du symbolisme", de 1925, publicado no livro Traité théorique et pratique de psychanalyse, além de um trabalho de análise literária que elaborou sobre Shakespeare, chamado Hamlet e o complexo de Édipo, de 1949. Dada a importância de ambos, serão apresentados a seguir de forma intercalada.

$\mathrm{Na}$ primeira das obras acima mencionadas, Jones refere-se ao símbolo como a parte da psicanálise que escapa ao arbítrio do analista, já que requisita um corpo de conhecimentos que, segundo ele, também extrapolam os limites da ciência psicanalítica, uma vez que se presentificam em outros domínios da cultura, sendo por isso objeto de interesse de outras ciências também. Verdade que lhe confere um interesse mais abrangente. $\mathrm{O}$ símbolo foi por ele definido como uma substituição de certas idéias, interesses e tendências por outras, acionada por dois processos, a saber: primeiro por extensão ou transferência de interesse de certas idéias mais simples, mais antigas e mais primitivas por idéias mais difíceis e mais complexas que simbolizariam as primeiras; em seguida, sua análise revela ser sempre uma representação de uma verdade que, por motivos afetivos ou intelectuais, foram concebidos em algum momento pelas mentes humanas. Após essa sucinta apresentação, fica pendente a caracterização da natureza e do modo de operação do símbolo. Antes, porém, Jones alerta para a necessidade de definir o 
símbolo em seu sentido limitado, isto é, no interior da psicanálise, antes de concebê-lo como de posse de diferentes domínios.

Para isso, Jones auxilia a compreensão acerca do tema elaborando uma relação de características comuns à noção de símbolo existentes, por exemplo: o símbolo define um processo de significação que percorre de uma idéia primária (mais essencial) a uma secundária (menos essencial). Em seguida, observa que a representação simbólica do elemento primário mantém uma relação com este baseada em algum elemento comum a ambos, uma semelhança suficiente para reconhecer traços equivalentes, que podem ser exteriores ou interiores, relação que se efetiva, sobretudo, em um processo inconsciente. Acrescenta que o símbolo é sempre mais breve e mais condensado do que a idéia que representa.

Completamente em acordo com Freud, Jones sustenta, em acréscimo, que a simbolização é o mais primitivo dos processos mentais, tanto ontogeneticamente como filogeneticamente. Assim, sua sobrevivência decorreria da capacidade mental de reversão às fases primitivas de sua evolução, observada, sobretudo, nos sonhos. Complementarmente, Jones assegura que uma segunda capacidade mental em questão, que é a de promover repressão, participa do processo de simbolização, já que para ele um símbolo constitui uma expressão manifesta de uma idéia ocultada, reservada e secreta, constituindo aqui também um disfarce promovido inconscientemente, visando não ser reconhecido pela consciência.

O ganho de terem sido apresentadas as características acima é a diferenciação para a compreensão de outros tantos processos mentais que seriam, em última instância, produtores de outras formas de representação figurada indireta, como a metáfora, a alegoria, a alusão, entre outras, diz Jones em seu artigo. Por conta disso, é mister compreender o símbolo em seu sentido estrito, cuja vantagem seria, diz ele, a de "compreender os níveis mais primitivos do desenvolvimento mental e suas ligações com o pensamento consciente" (1925, p. 209).

A esta altura da argumentação faz-se necessário oferecer conteúdo à diferenciação anunciada entre o símbolo e as demais formas de representação possíveis. Para isso, Jones desenvolveu no interior de seu artigo um tópico que chamou de "O simbolismo verdadeiro", justamente para atender a essa exigência teórica. A primeira característica distintiva já dita do chamado símbolo verdadeiro é a de representar elementos psíquicos inconscientes primitivos, o que favorece o fato de o sonhador 
não reconhecer como tal o símbolo que dispõe e utiliza. Uma segunda característica atribuída ao símbolo é a de possuir uma significação invariável. Antes, porém, da explicitação desta última, deve-se fazer uma ressalva a partir desse mesmo texto, pois, para Jones, um símbolo pode ter duas ou mais significações e, por isso, sua interpretação depender do contexto, das associações do sonhador como elemento auxiliar.

Contudo, isso quer dizer que de invariável há o fato de que, como diz Jones, "as variações possíveis de sua significação são muito limitadas" (1925, p. 217), sendo sua escolha dependente do contexto em que está inserido o sonhador, uma escolha, portanto, individual. Nessa perspectiva, Jones reconhece não haver lugar para interpretações aleatórias dos símbolos pelo analista. Essa última característica exige uma explicação relativa à autonomia significativa do símbolo, principalmente em relação aos fatores particulares. Registremos que uma possível autonomia só é justificável na medida em que se concebe o simbolismo como não estando condicionado somente a fatores individuais, uma vez que a capacidade de criar símbolos, longe de ser ilimitada, é por Jones concebida como fortemente restrita.

Para melhor explicitação dessa característica, devemos reconhecer uma sutileza, pois o símbolo é em grande parte independente de fatores particulares, pois, de fato, um sujeito não pode escolher aleatoriamente um símbolo para ser representante de uma idéia dada, mas, ao contrário, escolhe apenas, entre alguns símbolos possíveis, aquele que serviria para representar mais adequadamente uma determinada idéia inconsciente. Queremos dizer que pode ainda escolher um outro símbolo, é verdade, mas desde que tenha significação equivalente. Diz-se com isso que o símbolo escolhido não pode explicitar um sentido diverso daquele que the fora constituído anteriormente. O símbolo, portanto, antecede, nesta concepção, ao seu utente.

Cabe aqui um comentário com o objetivo de evitar mal-entendidos. Não se trata de postular, pelo menos em Jones e Freud, um tipo de inatismo em relação ao símbolo que, de alguma forma, seria até mesmo hereditário, visando sustentar sua autonomia, independência e uniformidade. De fato, para Jones, a uniformidade reconhecida deve-se ao fato de que longe de herdar, "ao contrário, cada um recria, por assim dizer, o simbolismo com os materiais de que dispõe" (1925, p. 218). Assim, a uniformidade do símbolo nada mais expressaria, e aqui estamos diante de uma verdadeira contribuição, do que a uniformidade do espírito humano no que diz respeito 
às suas tendências. Com isso, Jones está apontando, como ele diz, para a "uniformidade dos interesses fundamentais e permanentes da humanidade" (1925, p. 218). Nesse argumento, que carece de explicitação, estaria assim a origem da uniformidade do símbolo. Sua compreensão demanda o recurso à segunda obra de Jones, anteriormente mencionada, na qual analisa as fontes inconscientes da uniformidade, apontando para a presença do que chamou de temas fundamentais ou primordiais constitutivos da natureza do homem em geral. Nessa obra, Jones tenta compreender o significado psicológico do mito de Hamlet, reconhecendo ser ele recorrente em um vasto grupo de lendas, cujo histórico detalha. Também Freud apontou a presença do simbolismo nesse campo extra-onírico.

Jones aponta para o fato de que uma análise relativa aos conteúdos de diferentes mitos, em diferentes épocas e lugares, deve revelar que estes estão de forma invariável "vinculados a um número relativamente pequeno de temas primordiais, e mais, temas que evidenciam com clareza derivarem de correspondentes fantasias infantis" (1970, p. 127). Assim, Jones vincula sua pesquisa a fatores constitucionais, em que as assim chamadas fixações em fases da evolução sexual constituem bases ou suportes para a produção de símbolos.

Dessa maneira concebidos, os temas ou conteúdos dos mitos, assim como os símbolos que os compõem, poderiam ser compreendidos como produtos das fantasias inconscientes, isto é, do acúmulo de emoções, desejos e impulsos reprimidos, esquecidos ou jamais conscientizados que outrora povoaram a mente infantil. Em favor de sua tese, Jones aponta para um fato curioso que é a possibilidade de se encontrar, em muitas e diferentes partes do mundo, uma história típica com roteiro e enredo recorrentes. Em função dessa peculiaridade, ele postula a existência de pelo menos alguns temas fundamentais que, segundo sua conclusão, "são comuns à vida instintiva da raça" (1970, p. 127). Quer dizer com isso que os mitos, assim como as lendas e os símbolos, nada mais seriam do que expressões de tais temas.

Em favor de sua argumentação, Jones cita as semelhanças psicológicas observáveis no interior das diferentes versões da lenda de Hamlet, além de outras de outros povos, mesmo que aparentemente divergentes, mas cujo tema gira, por exemplo, em torno da incumbência conferida ao herói de vingar a morte do pai. Assim, o tema fundamental comum a todas seria, segundo ele, "o êxito de um jovem herói na luta para desalojar um pai rival" (1970, p. 128). Ele completa o argumento 
apontando para o fato de que, em diferentes lendas, a história da hostilidade ao pai é o tema predominante, enquanto, em outras, o que predomina é a afeição pela mãe, mas, diz ele, "regra geral, ambos os temas podem ser apontados, com maior ou menor clareza" (1970, p. 129).

Para compreender melhor as implicações de tais temas fundamentais, enfoquemos o quarto capítulo da mesma obra que ostenta o sugestivo título "A tragédia e a mente infantil". O êxito da compreensão da tragédia como tema fundamental, segundo o qual o herói luta para desalojar o pai rival, depende, segundo Jones, de dois temas, a saber, o sentimento de ciúme de uma criança e sua atitude em relação à morte. Tais temas completam-se e interpenetram-se na produção inconsciente do que aqui está sendo chamado de tragédia: triângulo edipiano como destino inexorável do ser humano. Cabe compreender a profunda e duradoura influência que esses temas infantis podem ou devem ter na maturidade do indivíduo como tiveram na da espécie.

Deve-se à psicanálise a descoberta de que, nos mitos como na vida em geral, encontramos processos mentais sobreviventes dos aspectos mais primitivos da vida mental que só perderam sua atuação graças às privações, às interdições, às reorientações, aos adiamentos e às renúncias que lhes foram impostas. Nesses termos, é que pode ser dito que a tragédia, no sentido do incesto e do parricídio apontados antes, nada mais seria do que uma herança, um destino que os homens trazem ao mundo, que se presentifica pelo "ressentimento sentido por um homem em relação ao pai, quando este perturba, como forçosamente acontece, a fruição do amor exclusivo da mãe pelo filho" (1970, p. 76). Com isso, Jones mostra que a universalidade da tragédia, em sua qualificação como tema primordial fundante dos conteúdos míticos, deve-se à expressiva contribuição do inconsciente, isto é, da mente infantil com sua hostilidade primordial sobrevivente no adulto. Nesse contexto é que a mente adulta, já ambivalente, dividida entre o amor atual ao pai e o ódio pretérito à sua tirania, pode representar simbolicamente tais atributos na pessoa de um rei ou equivalente.

Essas relações precisam ser mais bem explicitadas, pois, com relação ao problema do ciúme na infância, deve-se levar em conta a interpretação que a criança faz das restrições impostas aos seus privilégios e as suas satisfações imediatas. Nesse conflito, Jones bem aponta que a hostilidade para com o agente da interdição é proporcional à intensidade do afeto contrariado. A relação da intensidade do desejo com sua 
interdição não permanece sem consequiências quanto ao uso de símbolos. Assim é que passa a fazer sentido a interpretação de que o obstáculo à vingança encontrado em Hamlet não é mais que um problema moral derivado do conflito infantil que oferece contribuições inconscientes sobreviventes no adulto. Jones quer dizer com isso que as tragédias dos poetas e dramaturgos derivam, ou podem derivar, de aspectos da mente da criança que são inteiramente trágicos sobreviventes neles. A tragédia justifica-se, assim, como tema favorito de poetas e escritores, além de constituir, e isso não se pode negar, motivo relevante, constitutivo e central da maior parte das mitologias e religiões.

Dando complemento ao tema em questão, direcionemos agora a atenção para um conjunto de sonhos típicos analisados na Interpretação dos sonhos, que é o da morte de um ente querido, mas somente aqueles em que o sonho é seguido de angústia. Outras apresentações não seriam típicas como elas, diz Freud, pois nesses o sentido claro e invariável é o de que a pessoa morra efetivamente, mas somente considerado como desejo de outrora, do passado. Todavia para atribuir a característica de tipicidade e universalidade, o que permitiria dizer que corresponderia à representação de um desejo pretérito buscando reemersão no sonho de cada um dos homens, deveria este ter sido um sentimento cuja ocorrência deu-se igualmente em cada um dos sonhadores. Mas qual seria o fator que permitiria a postulação de tal recorrência e universalidade?

Em resposta, deve-se recorrer mais uma vez à vida mental suprimida das crianças, que seriam, segundo Freud, completamente egoístas, em que a luta pela satisfação plena de seus interesses não poupou nenhum dos rivais com que se deparou. Sobre esse sentimento, Freud, em uma nota acrescentada em 1919, dimensionando-o, diz que

o irrestrito amor próprio (o narcisismo) das crianças considera qualquer interferência um ato de lèse majesté, e seus sentimentos exigem (como o código draconiano) que qualquer crime desta ordem receba a única forma de punição que não admite graus. (1969c, p. 282)

Ou seja, a morte. Assim posto, o desejo do filho de que ocorra a morte do pai seria inevitável nessa fase, para todos os homens. Isso já seria suficiente para a afirmação de que, antes da inibição desses sentimentos, eles teriam sido comuns ao ser humano, sobrevivendo nos sonhos adultos, por exemplo, segundo representação típica. 
Outro grupo de sonhos típicos que vale mencionar, pois bem expressam a natureza libidinal ou pulsional do simbolismo, já que é explicado como recurso a um retorno universal a impressões da primeira infância, reside no que Freud chamou de sonho embaraçoso de estar despido. Este estaria respaldado no desejo infantil de exibir-se, justamente em um período isento da vergonha de fazê-lo. Em defesa de seu argumento, Freud exemplifica com a situação relatada no conto de Hans Andersen, "A roupa nova do imperador", no qual é reproduzida exatamente a circunstância do sonho de nudez.

Esses sonhos remeteriam recorrentemente à lembrança de um desejo infantil visando revivê-lo. Aponta assim para mais um percurso inevitável e inexorável da infância, não apenas do indivíduo, mas da espécie, o que proporcionaria a produção pretérita do símbolo, bem como sua reconstituição uniforme por cada membro da espécie, tornando-o típico. Ficamos assim com a nítida impressão de que o tópico dos sonhos típicos descrito por Freud e compartilhado por Jones, como visto, teve como precípua função demonstrar e exemplificar a universalidade da sexualidade infantil.

Por fim, podemos dizer que o tema primordial presente nos sonhos, nas histórias infantis, nas lendas e nos mitos apontam para atitudes infantis em relação ao próprio corpo e de filhos em relação aos pais, expressando uma estrutura que atravessa a história, presentificando-se graças a um processo que ficou conhecido pelo nome de Complexo de Édipo. Entendese assim que apontar para os argumentos que justificam e mostram como a estrutura do Édipo atravessa a história e se presentifica nas relações sociais e individuais ajuda a esclarecer a constituição e sobrevivência dos símbolos.

Com o que foi dito até agora, pode-se reconhecer, pela presença já admitida de uma uniformidade de interesses fundamentais e permanentes da humanidade, uma uniformidade do espírito humano quanto às tendências particulares que constituem a fonte do simbolismo. Assim, com base em tal uniformidade, podemos extrair conclusões relativas à natureza do homem em geral, tais como sua necessidade e seu interesse universal e permanente de reprimir a sexualidade infantil. A partir desse ponto da argumentação, as pulsões ditas sexuais, bem como as predisposições ou fixações delas decorrentes, passam a figurar com maior proeminência como determinantes do simbolismo, seja onírico, seja dos demais fatos da cultura. 
Devido a esses argumentos, pedimos licença para reforçar o tema que vem sendo aqui insistentemente abordado, que é o do fator constitucional na produção do simbolismo. O tema do fator constitucional não pode perder de vista a idéia freudiana de que em geral todo sintoma advém de uma mesma situação, a saber, "a necessidade de desviar as exigências libidinais do complexo edipiano" (1969m, p. 115). Acresce-se a isso a descoberta, já anunciada, de que todo sintoma neurótico pode ter um substrato formado em uma base pretérita que muitas vezes é manifestado por meio de um disfarce simbólico.

Pretendemos lançar mais luz sobre essa investigação, dando continuidade aos esclarecimentos referentes aos determinantes patogênicos e, por extensão, aos sonhos com seus simbolismos. Atentemos doravante à oposição dos conceitos de constitucional e de acidental, também expressos sob o binômio inato e adquirido. Para isso será feito recurso, ainda que de modo breve, a mais um artigo de Freud, "A disposição à neurose obsessiva", de 1913. Antes, porém, esclareçamos que mesmo alguns anos mais tarde, em 1937, em sua obra Análise terminável e interminável, Freud já alertava para o fato de que "não devemos exagerar a diferença existente entre caracteres herdados e adquiridos, transformando-a numa antítese; o que foi adquirido por nossos antepassados decerto forma parte importante do que herdamos" (p. 257). Assim, expõe de forma clara o conhecimento que pretende extrair da relação de tal par terminológico, precisando seu alcance.

Retomando os argumentos da obra antes referida, em que discute o problema da escolha da neurose, Freud relaciona, como dito, os conceitos de constitucional e de acidental, referindo-os em termos de inato e de adquirido, respectivamente. Nesse artigo, ele apresenta os determinantes patogênicos envolvidos na neurose como "aqueles que uma pessoa traz consigo para a sua vida, e aqueles que a vida lhe traz - o constitucional e o acidental" (1969 a, p. 341). Estabelece assim, à primeira vista, uma espécie de simetria entre os determinantes patogênicos. Por conta do que foi dito, faz-se inevitável um novo recurso à obra Análise terminável e interminável, na qual afirma, em conformidade com o que está sendo apresentado, que

a experiência analítica nos impôs a convicção de que mesmo conteúdos psíquicos específicos, tais como o simbolismo, não possuem outras fontes senão a transmissão hereditária, e pesquisas em diversos campos da antropologia social tornam possível supor 
que outros precipitados, igualmente especializados, deixados pelo primitivo desenvolvimento humano, também estão presentes na herança arcaica. (p. 257)

Nesse contexto, as associações da infância, isto é, das fases da evolução sexual, tanto do indivíduo como da espécie, subsistem no inconsciente de onde sob certas condições manifestam-se como símbolos. Assim também é que se pode compreender a sobrevivência de traços de simbolismos na linguagem, nos mitos, nas lendas, ainda que a humanidade evolua temporalmente. Uma tal concepção abre uma discussão de cunho polêmico, já que se refere à sobrevivência no indivíduo não só de esquemas constituídos em períodos primitivos, mas também em relação aos conteúdos gerados por tais esquemas. Com relação a isso, Freud informa-nos que "o que um dia veio à vida, aferra-se tenazmente à existência. Fica-se às vezes inclinado a duvidar se os dragões dos dias primevos estão realmente extintos" (1969e, p. 245).

Com isso, ele está, nunca é demais reafirmar, dizendo que a superação ou a substituição das fases pela qual passa o indivíduo, em seu curso ordenador da sexualidade, não se realiza de modo repentino e radical, mas de maneira a que partes da organização anterior sempre persistam ao lado da mais recente, podendo ser mantidas na configuração final. Se o mesmo pode ser aplicado à evolução da espécie, diz ele,

de todas as errôneas e supersticiosas crenças da humanidade que foram supostamente superadas não existe uma só cujos resíduos não perdurem hoje entre nós, nos estratos inferiores dos povos civilizados ou mesmo nos mais elevados estratos da sociedade cultural. (1969e, p. 245)

Assim, lança-se luz sobre a questão da sobrevivência de esquemas e conteúdos que se presentificam pelo símbolo.

Em seguida, será apresentada, como dito acima, uma discussão adicional, para finalizar este artigo, relativa à oposição adquirido/inato, na constituição do símbolo.

\section{SIMBOLISMO INATO, SIMBOLISMO ADQUIRIDO}

Apontar para a identificação do simbolismo como fruto de uma regressão em direção a um modo de representação mais simples e 
primitivo, cujo conteúdo seria, ou poderia ser, de natureza hereditária, é uma questão que demanda esclarecimentos. Nesse sentido, caminha a concepção freudiana de que as trilhas da escolha de um símbolo são aquelas

por onde passou toda a humanidade nas épocas mais remotas da civilização... trilhas de cuja continuada existência em nossos dias, sob o mais diáfano dos véus, encontram-se provas nos usos lingüísticos, nas superstições e nos costumes (1969c, p. 356),

ainda, no folclore, nos mitos populares, lendas, chistes, provérbios etc.

Podemos dizer em acréscimo que o sonhador é, nessa circunstância, sonhado pelo simbolismo, pois muito mais do que produtor de símbolos, o sujeito que sonha é visto nessa ótica como suporte de uma significação universal que se anuncia através dele. Mas adiantemos que, colocada dessa forma, a função de simbolização não deixa de constituir problema, principalmente quando é concebida como realizada alhures, lugar e tempo identificados acima.

A partir dessa perspectiva decorre, como consequiência, que a interpretação do símbolo deve, ou deveria, levar em conta uma genética, sob o risco de que sua determinação possa ser vista como um fato prévio de cultura transmitido "hereditariamente". Esse lugar conferido ao símbolo traz consigo a idéia de que ele se encontra supedito a uma simbólica geral, esta presente como uma língua sedimentada e arquivada nas representações inconscientes dos povos e que está expressa, como já dito, nas lendas, nos mitos, nos provérbios, na linguagem natural, enfim, nas diferentes manifestações culturais, pois, como diz Freud, "as coisas que estão hoje simbolicamente ligadas provavelmente estiveram unidas em épocas pré-históricas pela identidade conceitual e lingüística" (1969c, p. 384).

Pode-se dizer, por essa via, que o simbolismo típico deve corresponder à herança filogenética. Assim sendo, é também transmitido e fixado no uso lingüístico, na medida em que os indivíduos adquirem e transmitem suas linguagens. Essa concepção do simbolismo como herança de natureza filogenética precisa ser cuidadosamente considerada, ainda que se sabe que Freud nunca a abandonou, o que solicita esclarecimentos. Em sua obra Esboço de psicanálise, de 1938, afirmou que os sonhos também utilizam um material que não seria originário "nem da 
vida adulta de quem sonha, nem da sua infância esquecida" (p. 193), o que demanda explicações.

Assim considerado, só a influência arcaica de antepassados trazida ao mundo pela criança poderia explicar sua presença. Essa concepção alimenta a expectativa de um acesso à pré-história da humanidade pela via da expressão simbólica do inconsciente. Compreende-se também como é possível chegar a possuir e reconhecer símbolos pela via cultural, como dito há pouco, pela via de expressões idiomáticas carregadas deles, por exemplo. A título de ilustração, na Conferência X, Freud analisa uma seqüência de palavras derivadas da palavra "madeira"; matéria, mater, mãe, que proporciona o simbolismo da madeira como mãe. Essa vinculação permitiria, segundo ele, uma sobrevivência, uma herança observada atualmente, do uso simbólico de madeira como símbolo de mulher ou da mãe.

A perspectiva de um acesso à pré-história da humanidade referido no parágrafo anterior, dada sua dimensão, merece ser melhor apresentada. Compreende-se que, ao tratar do modo de expressão simbólico, Freud identifica um retorno a estados de nossa evolução intelectual há muito abandonados. Tal modo de representação pôde ser caracterizado como arcaico e regressivo. Assim sendo, o estudo do simbolismo permitiria esclarecer o início do desenvolvimento intelectual humano. Nunca é demais dizer que o que está sendo mencionado como pré-história ou arcaísmo, aos quais a elaboração onírica bem como o simbolismo fazem retroceder, deve ser compreendido de duas formas. Como diz Freud na Conferência XIII,

de um lado, a pré-história do indivíduo, sua infância; e, de outro, até onde cada indivíduo de alguma maneira recapitula, em forma abreviada, todo o desenvolvimento da espécie humana, a pré-história filogenética. (p. 201)

Mediante essa dicotomia indivíduo-espécie ou ontogênesefilogênese, Freud mostra que o simbolismo ou as conexões simbólicas, por não serem necessariamente adquiridas por aprendizado, "podem, com razão, exigir serem consideradas como herança filogenética" (1969i, p. 201). Nesse sentido, essa recapitulação que o indivíduo faz do desenvolvimento da espécie humana, ao realizar conexões simbólicas, só pode ser inconsciente e primitiva. Tal noção de algo adquirido na 
filogênese que se atualiza na ontogênese pode apontar, acreditamos, para um reforço do reconhecimento da natureza conservadora das pulsões, da sua universal tendência a restaurar estados anteriores de coisas.

Em reforço a esses argumentos, façamos referência a um comentário de Freud feito em sua análise na obra $O$ homem dos lobos, na qual justifica a relatividade entre a observação verídica ou a experiência real da cena das relações sexuais entre os pais por parte de seu paciente, também chamada de primária, e a possibilidade de esta ser uma fantasia do menino que passou a sonhar com lobos que o observavam do alto de uma árvore. Foi nessa obra, como já dito, que Freud reconheceu a cena primária, a sedução na infância e a castração como, diz ele, "inquestionavelmente, um dote herdado, uma herança filogenética" (p. 104). Mas é também na sequiência que ele afirma que tais conteúdos "podem também facilmente ser adquiridos pela experiência pessoal" (p. 104). Na tentativa de desfazer essa aparente contradição, será aprofundado o esclarecimento de seus termos.

De fato, o que Freud quer dizer, entendemos, é que os eventos ou as ocorrências, bem como as circunstâncias sofridas pelo homem em tempos pré-históricos, foram depois transmitidas segundo a forma de uma predisposição à sua reaquisição ontogênica. Agora sim podemos concluir, dirimindo a questão, que o indivíduo jamais herda o conteúdo, seja do sonho, seja do sintoma, mas o reconstitui ou o readquire, como se este ressurgisse mais uma vez, como diz Freud na mesma obra, "desde que persistissem as mesmas circunstâncias, como um evento concreto na experiência do indivíduo" (p. 105).

Essas circunstâncias idênticas foram, algumas páginas adiante, identificadas como possíveis ou derivadas de esquemas filogeneticamente herdados, entre eles o complexo de Édipo, que possuem uma sobrevivência e atualidade independentes do indivíduo. Mas foi na Conferência XXII que Freud explicitou, expondo sobre a natureza do desenvolvimento dos instintos do ego e dos instintos sexuais, que ambos são, como diz, "no fundo, heranças, recapitulações abreviadas do desenvolvimento pelo qual toda a humanidade passou, desde épocas primitivas, por longos períodos de tempo" (p. 357).

Isso fica claro quando diz que, "no caso dos seres humanos, esse ponto de vista filogenético... é herdado, não obstante é de aquisição recente no desenvolvimento do indivíduo" (1969o, p. 357) e completa: "provavelmente porque as mesmas condições que impuseram sua 
aquisição persistem e continuam a operar em cada indivíduo" (p. 357). Com isso, crê-se não restar dúvida sobre o que se quer e pode-se dizer com o herdado psicologicamente, em termos freudianos.

A essa altura pode ser excluída da argumentação o aspecto vacilante que o leitor deve ter percebido anteriormente relativo à relação do adquirido e do inato. Com isso, queremos dizer que há concordância sem problemas com um possível inatismo desde que atribuído à estrutura ou ao esquema disposicional reconstruído e recapitulado em cada indivíduo e não necessariamente aos conteúdos psíquicos que, como visto, de certo apenas acompanham coincidentemente a recapitulação e atualização dessa estrutura.

Vemos, dessa forma, que a articulação de uma ontogênese sobre a filogênese redimensiona o lugar e a importância do indivíduo e da cultura como sedes da produção simbólica, isto é, o vínculo simbólico é também, a partir de agora, construído por um trabalho, digamos, do sujeito na cultura. Acrescentemos que a questão da relação do herdado com o adquirido pode ser ainda mais iluminada com recurso a uma outra obra, de 1937, Análise terminável e interminável, onde reconhece a existência de um exagero quando se trata de diferenciar caracteres herdados ou adquiridos. Com isso, Freud pretende reduzir a condição de antítese que normalmente é atribuída ao par terminológico. Diz ele que "o que foi adquirido por nossos antepassados decerto forma parte importante do que herdamos" (p. 257), mas não mais do que isto, já que a elucidação do símbolo ou do sintoma é proporcionada por fatores da infância do indivíduo.

Assim é que se pode compreender como é que conteúdos psíquicos específicos, como o simbolismo, podem ter fontes de transmissão reconhecidas como hereditárias. Sempre lembrando que a questão da determinação hereditária não precisa ser pensada do ponto de vista biológico, uma vez que é do psíquico que falamos, no qual o conceito de hereditariedade ganha contorno específico. O que a leitura de Freud permite compreender é que há uma historicidade presente no conceito de hereditariedade psíquica, uma vez que há sim uma repetição cultural desde os primórdios da humanidade e que, à sua maneira, "formata" as vicissitudes do sujeito. Isso faz com que a pré-história do sujeito coincida com a da humanidade.

Dessa forma, o que resta afirmar é que Freud mantém sua perspectiva empirista, já que alguém teve em alguma fase do desenvolvimento 
da humanidade as experiências geradoras de símbolos agora repetidos. Quer dizer, a experiência é condição da hereditariedade que, por sua vez, condiciona-a. Assim, podemos enfim dizer que o simbolismo baseiase nas repressões efetuadas por gerações anteriores, enquanto se exige de cada nova geração que mantenha esse simbolismo efetuando as mesmas repressões.

\section{ABSTRACT}

This article presents research into the concept of symbolism as conceived by Freud and his collaborator, Ernest Jones. Reclaiming the concept of symbolism involves verifying its statute, constitution, working mechanism, organization, origins and influences, which, one would hope, ought to make possible the recognition of its role within Freudian analysis itself.

Key words: psycho-analysis; language; symbolism; dreams; symptom.

\section{REFERENNCIAS}

FREUD, S. A interpretação dos sonhos. Rio de Janeiro: Imago, 1969c. v. IV e V.

. Algumas notas adicionais sobre a interpretação de sonhos como um todo. Rio de Janeiro: Imago, 1969d. v. XIX. . Artigos sobre metapsicologia. Rio de Janeiro: Imago, 1969g. v. XIV. Cinco lições de psicanálise. Rio de Janeiro: Imago, 1969h. v. XI. . Conferências introdutórias sobre psicanálise. Rio de Janeiro: Imago, 1969i. v. XV e XVI. Esboço de psicanálise. Rio de Janeiro: Imago, 1969j. v. XXIII. . Moisés e o monoteísmo. Rio de Janeiro: Imago, 1969n. v. XXIII. . Novas conferências introdutórias sobre psicanálise. Rio de Janeiro: Imago, 1969o. v. XXII. . Os sonhos no folclore. Rio de Janeiro: Imago, 1969p. v. XII.

. Suplemento metapsicológico à teoria dos sonhos. Rio de Janeiro: Imago, 1969q. v. XIV.

. Totem e tabu. Rio de Janeiro: Imago, 1969r. v. XIII.

Três ensaios sobre a teoria da sexualidade. Rio de Janeiro: Imago, 1969s. v. VII. 
Uma ligação entre um símbolo e um sintoma. Rio de Janeiro: Imago, 1969t. v. XIV.

Projeto de uma psicologia. Rio de Janeiro: Imago, 1995.

GARCIA-ROZA. L. A . Freud e o inconsciente. Rio de Janeiro: Zahar, 1983.

Acaso e repetição em psicanálise, uma introdução à teoria das pulsões. Rio de Janeiro: Zahar, 1986.

JONES, E. La théorie du symbolisme. In: Traité théorique et pratique de psychanalyse. Paris: Payot, 1925.

. Hamlet e o complexo de Édipo. Rio de Janeiro: Zahar, 1970.

Vida e obra de Sigmund Freud. Rio de Janeiro: Zahar

MONZANI, L. R. Filosofia da psicanálise. São Paulo: Brasiliense, 1991.

Freud, um pensamento em movimento. Campinas: Unicamp, 1989.

STEKEL, W. El lenguaje de los suenos. Buenos Aires: Ediciones Imán, 1954.

WOLLHEIM, R. As idéias de Freud. São Paulo: Círculo do Livro, 1971. 
